\title{
VEGF IMMUNOEXPRESSION IN PENILE CARCINOMA ${ }^{1}$
}

\author{
Antonio Carlos Pereira Martins ${ }^{2}$ \\ Sérgio Britto ${ }^{3}$ \\ Clécio Takata ${ }^{4}$ \\ Haylton Jorge Suaid ${ }^{5}$ \\ Adauto José Cologna ${ }^{6}$ \\ Silvio Tucci $\mathrm{Jr}^{6}$ \\ Whemberton M. Araujo
}

\begin{abstract}
Objective - To investigate the vessel endothelial growth factor (VEGF) as a risk factor in squamous cell carcinoma of the penis (SCCP). Methods - Fortyseven patients with penile carcinoma were evaluated retrospectively. The mean age and standard deviation were $61.1 \pm 11.7$ years. All of them were treated by penectomy and those with positive nodes underwent groin lymphadenectomy. Tumor grading was $35 \mathrm{G} 1$ and 12 G2/3. Primary lesion stage was 24 pT1 and 23 pT2-4. Positive inguinal nodes were observed in 15 patients. Selected paraffin embedded sections were submitted to VEGF immunohistochemical analysis by the avidin-biotin-immunoperoxidase method with antigen retrieval. All slides were examined using an automatic analyzer system and the proportion of labeled cells in 10 high magnification power fields (400X) were recorded in a blind analysis. Results - Median (\%) labeling index was 2.3 in G1 versus 2.2 in G2/3 tumors $(\mathrm{p}=0.60)$, and 4.0 in $\mathrm{pT} 1$ versus $1.8 \mathrm{pT} 2-4$ tumors $(\mathrm{p}=0.10)$. The respective data for $\mathrm{pN} 0$ patients was 2.8 and for $\mathrm{pN}+$ was $2.1(\mathrm{p}=0.20)$. Survival curves showed no association with patients survival. Conclusion - In squamous cell carcinoma of the penis the VEGF immunoexpression has no association with tumor grade or stage, as well as with patient survival. Disponível em URL: http://www.scielo.br/acb
\end{abstract}

Key Words - Penile carcinoma, squamous cell carcinoma of the penis, CD34.

\section{INTRODUCTION}

Conventional risk factors such as tumor grade and $\mathrm{T}$ stage are good prognostic markers for squamous cell carcinoma of the penis (SCCP). In several series they were able to predict disease progression and survival in-groups of patients. But, the management of patients who presents with clinically negative inguinal nodes in whom the primary lesion invades the corpora (pT2-4) is controversial. Approximately $20 \%$ of such patients will have occult metastases ${ }^{1,2,3}$. The individual prognostic within a group of stratified patients is unreliable. This possibly is a consequence of independent risk factors that are not identified through the conventional methods such as an especially aggressive cell clone bearing molecular changes which are not associate with a morphological label. The search for new molecular tumor markers and its association with the outcome is warranted. Recently, Martins et al. ${ }^{4}$ reported for the first time that the immoexpression of p53 protein is an independent risk factor for metastasis of SCCP, stronger than tumor grade or stage in a multivariate analysis. Another study using a colorimetric messenger RNA in situ hybridization assay for VEGF, metalloproteinase and $\mathrm{E}$ cadherin revealed a positive correlation between VEGF and metalloproteinase 9 expression and lymphatic spread in $>$ pT1 penile carcinomas 5 .

\footnotetext{
This research was carried out with FAPESP support at HCFMRP-USP.

Professor of Urology - FMRP-USP

Assistant Professor of Pathology - FMRP-USP

Student of Medicine - FMRP-USP

Associate Professor of Urology - HCFMRP-USP

Assistant Professor of Urology - FMRP-USP

Postgraduation student - FMRP-USP
} 
In this research we investigate the role of angiogenesis through vessel endothelialgrowth factor (VEGF) immunoexpression as a risk factor in patients with SCCP.

\section{METHODS}

Between January of 1976 and December of 1998, 47 patients with the diagnosis of SCCP were treated at our hospital and selected for this study. Inclusion criteria were adequate specimens for histology and immunohistochemistry, and a followup of 5 years or more. Age range varied from 33 to 88 years (mean \pm SD $=61.1 \pm 11.7$ years). The tumor was staged retrospectively according to 1999 TNM system ${ }^{6}$. The grading system adopted was: differentiated (G1), moderately differenciated (G2) and undifferentiated (G3) ${ }^{4}$.

Primary treatment consisted of total (4) or partial (43) penectomy. Approximately 6 weeks after penectomy 10 patients underwent bilateral inguinal lymphadenectomy in consequence of clinically positive groin nodes. The histology confirmed that all of them were $\mathrm{pN}+$. The remaining 37 patients with non palpable groin nodes were followed, of whom 5 required delayed inguinal lymphadenectomy for clinical relapse. Metastasis was confirmed histologically in all 5 cases.

Except for patients who died of disease followup varied from 5 to 20 years (median 9).

Histological slides were revised to select representative areas of the primary lesion, and corresponding formalin fixed, paraffin embedded tissue blocks were sliced for VEGF immunohistochemical analysis. Two $4 \mathrm{~mm}$ blank sections were cut from each designated block. Slices were then mounted on polyL-lysune coated slides, de-waxed in xylene and rehydrated with graded ethanol to water. Sections were then incubated with $3 \%$ hydrogen peroxide in absolute methanol for 20 minutes. Immunohistochemical reaction was performed by the avidin-biotinimmunoperoxidase method with antigen retrieval ${ }^{7}$ using antibody anti-VEGF. The immunohistochemical preparations were counterstained with hematoxilin. Slices of a known bladder carcinoma and primary antibody replaced by mouse serum were used as positive and negative controls. All slides were examined using an automatic analyzer system (KS-400, Zeiss). The proportions of stained cells in 10 high magnification power fields $(400 \mathrm{X})$ were determined in a blind analysis. Tumors with $>5 \%$ of stained cells were called VEGF positive.

The median values of proportion of stained cells between groups were compared by the Mann-Whitney test. Survival curves were compared by the Logrank test. $\mathrm{P}$ values higher than 0.05 are not significant.

\section{RESULTS}

The association between VEGF expression and tumor grade, $T$ stage and metastases is showed in Tables 1,2 and 3.

Table 1 - Relationship between tumor grade and VEGF immunoexpression.

\begin{tabular}{cccc}
\hline \multirow{2}{*}{ Tumor Grade } & N & \multicolumn{2}{c}{ \% Labeling Index* } \\
\cline { 3 - 4 } & & Mean \pm SD & Median \\
\hline 1 & 35 & $4.2 \pm 4.5$ & 2.3 \\
$2+3$ & 12 & $18.5 \pm 38.1$ & 2.2 \\
\hline
\end{tabular}

* Labeling index: percent of stained cells; Two-tailed P $=0.60$ (Mann-Whitney test)

Table 2 - Tumor T stage versus VEGF expression.

\begin{tabular}{cccc}
\hline \multirow{2}{*}{ Tumor Stage } & N & \multicolumn{2}{c}{ Labeling Index* } \\
\cline { 3 - 4 } & & Mean \pm SD & Median \\
\hline pT1 & 24 & $8.8 \pm 19.9$ & 4.0 \\
pT2-4 & 23 & $6.9 \pm 20.5$ & 1.8 \\
\hline
\end{tabular}

* Two-tailed P is 0.10 (Mann-Whitney test) 
Table 3 - Tumor N/M stage versus VEGF expression.

\begin{tabular}{cccc}
\hline Tumor Stage & N & \multicolumn{2}{c}{ Labeling Index* } \\
\cline { 3 - 4 } & & Mean \pm SD & Median \\
\hline N0M0 & 32 & $10.5 \pm 23.8$ & 2.8 \\
N/M+ & 15 & $2.3 \pm 2.3$ & 2.1 \\
\hline
\end{tabular}

* Two-tailed P is 0.20 (Mann-Whitney test)

The relationship between VEGF immunoexpression with patients survival is showed on Figure 1.

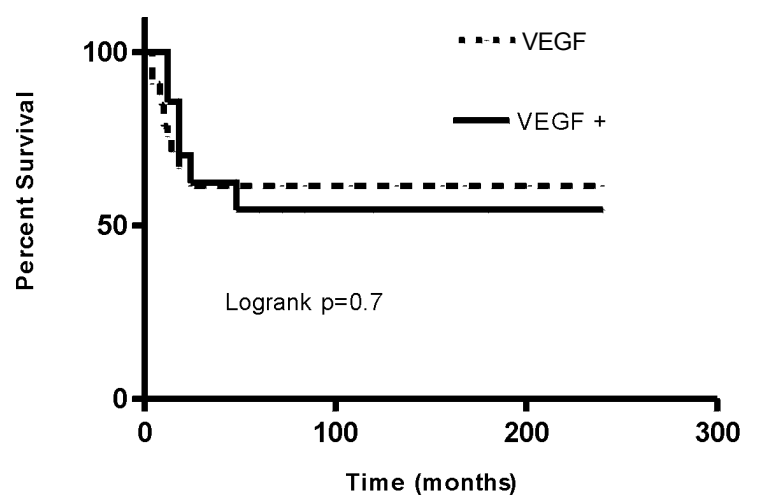

Figure 1 - Survival curves according to VEGF immunoexpression.

\section{DISCUSSION}

Angiogenesis does not depend exclusively on VEGF expression since it can be induced by other proteins of the transmission chain of Ras gene, and also be influenced by hypoxia ${ }^{8}$.

Our data did not show any correlation between the immunohistochemical expression of VEGF and tumor grade, stage or patients survival. But, such association was reported for tumors of several organs such as prostate ${ }^{9}$, pancreas ${ }^{10}$, lung ${ }^{11}$ and colon $^{12}$. Another study using a colorimetric mRNA in situ hybridization assay for VEGF revealed a positive correlation between VEGF expression and lymphatic spread in penile carcinomas 5 . The VEGF is a growing family of factors and it is not possible that the primary monoclonal antibody employed in our experiment (Santa Cruz, USA) has the same sensitivity and specificity than others used abroad. Another explanation our conflicting results may lay in the series characteristics.

\section{CONCLUSIONS}

In squamous cell carcinoma of the penis the VEGF immunoexpression has no association with tumor grade or stage, as well as with patient survival.

\section{REFERENCES}

1. Ayyapan K, Ananthakrishnam N, Sankaran V. Can regional lymph node involvement be predicted in patients with carcinoma of the penis? Br J Urol 1994;73:549-53.

2. Horenblas S. Lymphadenectomy for squamous cell carcinoma of the penis. Part 1: Diagnosis of lymph node metastasis. BJU International 2001;88:467-72.

3. McDougal WS, Kirchner FKJr, Edwards RH, Killion LT. Treatment of carcinoma of the penis : the case for primary lymphadenectomy. J Urol 1986;36:38-41.

4. Martins ACP, Faria SM, Cologna AJ, Suaid HJ, Tucci Jr S. Immunoexpression of $\mathrm{p} 53$ protein and proliferating cell nuclear antigen in penile carcinoma. J Urol 2002;167:89-93.

5. Slaton JW, Inoue K, Morganstern N, Tamboli P, Ayala A, Dinney CPN, Pettaway CA: Metastasis-related gene expression predicts for positive inguinal nodes in squamous penile carcinoma. J Urol 2000; 163:641A.

6. Hermanek P, Hutter RVP, Sobin LH, Wagner G, Wittekind C. T,N.M. Atlas, $4^{\text {th }}$ ed., New York, Springer-Verlag, 1999, pp.264.

7. Taylor CR, Shi SR, Chaiwun B, Young L, Iman AS, Cote RJ. Strategies for improving the immunohistochemical staining of various intranuclear prognostic markers in formalin-paraffin sections: androgen receptor, estrogen receptor, progesterone receptor, $\mathrm{p} 53$ protein, proliferation cell nuclear antigen and Ki-67 antigen revealed by antigen retrieval techniques. Hum Pathol 1994;25:263-70.

8. Sivridis E, Giatromanolaki A, Gatter KC, Harris AL, Koukourakis MI. Tumor and Angiogenesis Research Group: Association of hypoxia-inducible factors 1alpha and 2alpha with activated angiogenic pathways and prognosis in patients with endometrial carcinoma. Cancer 2002;95:1055-63.

9. Latil A, Bieche I, Pesche S, Valeri A, Fournier G, Cussenot O, Lidereau R. VEGF overxpression in clinically localized prostate tumors and neutropilin-1 overxpression in metastatic forms. In J Cancer 2000;89:167-71.

10. Niedergethmann M, Hildenbrand R, Wostbrock B, Hartel M, Sturm JW, Richter A, Post S. High expression of vascular endothelial growth factor predicts early recurrence and poor prognosis after curative resection for ductal adenocarcinoma of the pancreas. Pancreas 2000;25:122-9.

11. Yuan A, Yu CJ, Chen WJ, Lin FY, Kuo SH, Luh KT, Yang PC. Correlation of total VEGF mRNA and protein expression with histologic type, tumor angiogenesis, patient survival and timing of relapse in non-small-cell lung cancer. Int J Cancer 2000; $89: 475-83$

12. Han J, Xia C, Gao J, Xing C, Yang X, Tang X, Qiu F, Du Y. Expression of vascular endothelial growth factor in colorectal cancer and its clinical significance. Zhonghua Yi Xue Za Zhi 2002;82:481-3.

\section{Address}

Antonio Carlos Pereira Martins

Faculdade de Medicina de Ribeirão Preto - USP

Av. Bandeirantes n ${ }^{\circ} 3900$, Ribeirão Preto, SP

CEP: $14048-900$

e-mail: acpmartins@convex.com.br 